1

2

3

4

5

6

7

8

9

10

11

12

Therapeutic Potential of Targeting Sphingosine Kinases and Sphingosine 1-phosphate in Hematological Malignancies

4

C Evangelisti ${ }^{1}, \mathrm{C}$ Evangelisti ${ }^{2}, \mathrm{~F}$ Buontempo ${ }^{1}, \mathrm{~A} \mathrm{Lonetti}^{1}$, E Orsini ${ }^{1}$, F Chiarini ${ }^{2}$, JT Barata $^{3}$, S Pyne $^{4}$, NJ Pyne ${ }^{4}$ and AM Martelli ${ }^{1}$

${ }^{1}$ Department of Biomedical and Neuromotor Sciences, University of Bologna, Bologna, Italy;

${ }^{2}$ Institute of Molecular Genetics, National Research Council-Rizzoli Orthopedic Institute and Muscoloskeletal Cell Biology Laboratory, IOR, Bologna, Italy; ${ }^{3}$ Instituto de Medicina Molecular, Faculdade de Medicina da Universidade de Lisboa, Lisbon, Portugal; ${ }^{4}$ Strathclyde Institute of Pharmacy and Biomedical Sciences, University of Strathclyde, Glasgow, Scotland, UK

Running title: SPHK/S1P in malignant hematological disorders

Correspondence: Professor AM Martelli, Department of Biomedical and Neuromotor Sciences, University of Bologna, via Irnerio 48, 40126 Bologna BO, Italy; E-mail: alberto.martelli@unibo.it; Phone: +39 051 2091580; Fax: +39 0512091695

\title{
The authors declare no conflict of interest.
}




\section{Abstract}

Sphingolipids such as ceramide, sphingosine, and sphingosine 1-phosphate (S1P), are bioactive molecules that have important functions in a variety of cellular processes, which include proliferation, survival, differentiation and cellular responses to stress. Sphingolipids have a major impact on determination of the cell fate by contributing to either cell survival or death. While ceramide and sphingosine are usually considered to induce cell death, S1P promotes survival of cells. Sphingosine kinases (SPHKs) are the enzymes that catalyze the conversion of sphingosine to S1P. There are two isoforms, SPHK1 and SPHK2, which are encoded by different genes. SPHK1 has recently been implicated in contributing to cell transformation, tumor angiogenesis, and metastatic spread, as well as cancer cell multidrug-resistance. More recent findings suggest that SPHK2 also has a role in cancer progression. This review is an overview of our understanding of the role of SPHKs and S1P in hematopoietic malignancies and provides information on the current status of SPHK inhibitors with respect to their therapeutic potential in the treatment of hematological cancers.

Key words: apoptosis, ceramide, drug-resistance, leukemia, lymphoma, multiple myeloma, sphingosine, sphingosine 1-phosphate 7

8
49 5 1 (1) 


\section{INTRODUCTION}

The most spectacular success so far in the field of targeted therapy of hematological malignancies has been the introduction of the BCR/ABL1 tyrosine kinase ATP-competitive inhibitor, imatinib, which produces a major cytogenetic response in the vast majority of newly-diagnosed chronic phase chronic myelogenous leukemia (CML) patients. However, imatinib resistance/intolerance have led to the development of additional tyrosine kinase inhibitors, which have demonstrated effectiveness as salvage therapies or alternative first-line treatments for $\mathrm{CML}^{1}$.

CML is a unique disorder in that BCR/ABL1 is sufficient for disease initiation and progression. In contrast, most hematological malignant disorders are more complex and display multiple genetic and/or epigenetic aberrations which affect many signaling pathways, including those responsible for cell proliferation, survival, differentiation, metabolism and drug-resistance. It is highly unlikely that single targeted agent therapy will be sufficient for successful treatment of these more complex diseases. Therefore, the use of rational combinations of appropriately targeted drugs might provide viable treatment options and these could also be combined with traditional chemotherapy.

In 1996, the "sphingolipid rheostat" model was proposed, based on evidence showing that ceramide, sphingosine and sphingosine 1-phosphate (S1P) differentially regulate cellular signaling pathways involved in proliferation and survival. The suggestion was that growth factors, cellular stress and inflammatory mediators might alter the balance between ceramide and S1P in order to control cell fate ${ }^{2,3}$. This was supported by the finding that ceramide induces cell growth arrest and apoptosis, whereas S1P induces cell growth. Over the following years, many efforts were made to elucidate the molecular signaling pathways by which ceramide and S1P cause their effects. These studies have also revealed important roles for ceramide and S1P in the pathology of several human disorders, including cancer ${ }^{4}$. Therefore, from a therapeutic perspective, these findings have provided the rationale for manipulating the ceramide/S1P balance with small molecule inhibitors, in order to, for example, induce apoptosis of cancer cells. One particular target regulating the sphingolipid rheostat is the enzyme, sphingosine kinase (SPHK), which catalyzes the formation of 
S1P. There are two isoforms, SPHK1 and SPHK2 that are encoded by different genes and which are involved in hematological malignancies ${ }^{5}$. In this review, we focus on the emerging evidence that SPHKs may indeed represent a target for innovative treatment of patients suffering from hematological malignant disorders.

\section{Sphingosine 1-phosphate}

Ceramide, sphingosine and S1P are bioactive sphingolipids involved in a wide range of cellular processes, including cell proliferation, apoptosis, autophagy, motility, angiogenesis and inflammation. Ceramide can be deacylated by ceramidases to form sphingosine, which in turn is phosphorylated by SPHKs to produce S1P. S1P can then be dephosphorylated by S1P phosphatases or lipid phosphate phosphatases or irreversibly cleaved by S1P lyase (Figure 1). S1P is generally produced within the cell and binds to either intracellular proteins (see below) or, upon export, functions as a ligand for five heterotrimeric $\mathrm{G}$ protein-coupled receptors, referred to as $\mathrm{S}_{1} \mathrm{P}_{1}$ to $\mathrm{S} 1 \mathrm{P}_{5} . \mathrm{S} 1 \mathrm{P}$ binding to these receptors regulates angiogenesis, lymphocyte trafficking through blood and lymphoid organs, inflammation and cell transformation. This involves activation of signaling pathways that include Ras/MEK/extracellular signal-regulated kinase-1/2 (ERK-1/2), phosphoinositide 3-kinase (PI3K)/Akt/mammalian target of rapamycin (mTOR), Rac, Rho and phospholipase $\mathrm{C}$ (PLC) ${ }^{6}$. S1P is exported from cells through both ATP-dependent and independent mechanisms. ATP-dependent export mechanisms, such as in erythrocytes, mast cells, and platelets, involve members of the ATP-binding cassette (ABC) super family of transporters, including $\mathrm{ABCC} 1, \mathrm{ABCA} 1$ and $\mathrm{ABCG} 2$. The spinster homolog 2 (SPNS2) is a transporter which plays an important role in exporting S1P from endothelial cells and B- and T-lymphocytes via an ATP-independent mechanism ${ }^{7}$.

The regulation of intracellular targets by S1P binding also affects inflammation, immediate early gene expression and replicative immortality. For example, tumor necrosis factor (TNF) receptorassociated factor 2 (TRAF2) is an essential component in the TNF- $\alpha /$ nuclear factor- $\kappa \mathrm{B}(\mathrm{NF}-\kappa \mathrm{B})$ 
signaling pathway. It has been reported that S1P confers E3 ligase activity on TRAF2. TRAF2 catalyzes the Lys63-polyubiquitination of the receptor-interacting serine/threonine-protein kinase 1 (RIPK1), which serves as a scaffold platform for activation of the NF- $\kappa \mathrm{B}$ pathway and regulates cell survival and inflammatory and immune responses. However, the role of SPHK1 in TRAF2NFKB signaling is controversial. For instance, studies have shown that TNF $\alpha$-mediated activation of NF- $\mathrm{KB}$ and cytokine production is unaffected in macrophages deficient in both SPHK1 and SPHK2. S1P has also been shown to bind to and inhibit the activity of histone deacetylases (HDACs) 1 and 2 leading to increases in histone acetylation, thereby inducing expression of c-Fos and the cell cycle negative regulator, p21. Furthermore, S1P binds to human telomerase reverse transcriptase (hTERT) to increase its stability, enhance telomere integrity and prevent senescence. The binding of S1P to hTERT prevents its interaction with makorin ring finger protein 1 (MKRN1), an E3 ubiquitin ligase that polyubiquitinates hTERT and promotes its proteasomal degradation (see ${ }^{6}$ for details).

A role for S1P in cancer was initially suggested by the finding that the concentration of S1P in the plasma of cancer patients is elevated, suggesting that S1P might promote tumor growth via S1P receptors ${ }^{8,9}$. Indeed, S1P binding to S1P receptors promotes carcinogenesis through crosstalk with different receptor tyrosine kinases that involves transactivation ${ }^{10,11}$, integrative S1P-receptor tyrosine kinase complex formation ${ }^{12}$ and regulatory loop amplification ${ }^{13}$. Clinical relevance is evident from studies showing that high expression of SPHK1 and $\mathrm{S}_{1} \mathrm{P}_{1}$ and $\mathrm{S}_{1} \mathrm{P}_{3}$ receptors in estrogen positive breast tumors are associated with poor prognosis ${ }^{14}$.

\section{Sphingosine kinases}

SPHK1 and SPHK2 belong to a family of proteins highly conserved throughout eukaryotes, ranging from yeasts to humans. SPHK1 and SPHK2 genes are located on human chromosome 17 (17q25.2) and 19 (19q13.2), respectively. Although the human isoforms vary considerably in size (384 and 
618 amino acids for SPHK1 and SPHK2, respectively), they share $80 \%$ similarity and $45 \%$ overall sequence identity. SPHK2 contains additional regions at its $\mathrm{N}$-terminus that are involved in regulating membrane localization and a proline-rich insert in the middle of its amino-acid primary sequence (Figure 2). SPHKs display differential expression during development, as well as different subcellular localization. Indeed, SPHK2 possesses a functional nuclear localization signal (NLS) and can shuttle in and out of the nucleus. In addition to being localized in the cytosol and the plasma membrane, SPHK2 can associate with mitochondria and under stress conditions with the endoplasmic reticulum (ER). In contrast, SPHK1 is distributed in the cytosol and the plasma membrane. These observations indicate that SPHKs have distinct biological roles. However, mice with genetic deletion of either Sphk1 or Sphk2 developed normally, suggesting there is considerable functional redundancy. In contrast, deletion of both genes is embryonic lethal due to severely disturbed neurogenesis and angiogenesis ${ }^{15,16}$.

\section{Sphingosine kinase 1}

Three SPHK1 isoforms have been identified, which result from alternative splicing and differ only in their N-terminal regions ${ }^{15}$. SPHK1a is expressed in the central nervous system, the kidney, endothelial cells, megakaryocytes and platelets. SPHK1a appears to be the main contributor to plasma S1P levels. In contrast, SPHK1b has a 14 amino-acid N-terminal extension. SPHK1c (sometimes referred also to as SPHK1b based on antibody identification of 42 versus $51 \mathrm{kDa}$ isoforms) has an 86 amino-acid extension at the N-terminus. The N-terminal 86 amino-acid extended SPHK1 isoform (termed here SPHK1b) is very much more stable in cells compared with SPHK1a and appears to be associated with chemo-resistance of cancer cells. For example, the sphingosine kinase inhibitor, SKI-II [SKi, 2-(p-hydroxyanilino)-4-(p-chlorophenyl) thiazole)] induces the proteasomal degradation of SPHK1a and SPHK1b in androgen-sensitive LNCaP prostate cancer cells and this is associated with apoptosis of these cells ${ }^{17}$. SKI-II also induces proteasomal degradation of SPHK1a in androgen-independent LNCaP-AI cells, but fails to reduce 
SPHK1b levels ${ }^{17}$ and these cells do not undergo apoptosis. It should be noted that most studies focus on SPHK1a and the relative importance of the splice variant forms remains unclear. SPHK1 exhibits intrinsic catalytic activity ${ }^{18}$, which can be further up-regulated by a wide range of growth factors, cytokines, hormones and adhesion molecules which include epidermal growth factor (EGF), TNF- $\alpha$, androgens and platelet endothelial cell adhesion molecule (PECAM) -1. Activation of SPHK1 is via phosphorylation, catalyzed by ERK-1/2. ERK-1/2 catalyzes phosphorylation of SPHK1 at Ser $225^{19}$, which induces its activation and translocation from the cytoplasm to the plasma membrane and which also involves its binding to calcium- and integrin-binding protein 1 (CIB1) ${ }^{20}$. SPHK1 phosphorylation is transient, being reversed by protein phosphatase 2A (PP2A) 21. The S1P formed by SPHK1 can be released from cells to activate S1P receptor-mediated signaling, in a process termed "inside-out" signaling ${ }^{22}$.

Over-expression of SPHK1 induced neoplastic transformation of NIH3T3 fibroblasts, although it is not yet established whether SPHK1 is an oncogene as there are no reported activating mutations in cancer. Vadas et al. ${ }^{23}$ have defined a non-oncogenic addiction of cancer cells to SPHK1. Nevertheless, SPHK1 expression levels are up-regulated in several malignancies, including glioblastoma, non-Hodgkin lymphomas (NHL), prostate cancer, colon adenocarcinoma, non-smallcell lung cancer and chemoresistant acute leukemia ${ }^{24,25}$. Moreover, high SPHK1 expression levels in tumors is associated with poor patient survival in glioblastoma, gastric cancer, breast cancer and cholongiocarcinoma ${ }^{4}$. It should be noted that in some of these studies SPHK1 mRNA levels were analyzed $^{24,25}$, whereas in others, SPHK1 protein levels were investigated ${ }^{13,14,24,25}$.

A systematic review and meta-analysis of literature data on SPHK1 expression in human cancers as compared to healthy tissue has been recently published ${ }^{26}$. This analysis included 4,673 patients from 7 countries and 19 types of cancer. Overall, this study demonstrated that SPHK1 positivity/high expression in tumors was significantly associated with various types of cancers and reduced 5-year and overall survival. The important role played by SPHK1 in cancer cell biology is substantiated by the fact that chemical targeting of SPHK1 reduced tumor growth in xenograft 
182

183

184

185

186

187

mouse models of established human tumor cell lines ${ }^{27-30}$ and decreased therapeutic resistance in prostate cancer $^{31-33}$, pancreatic adenocarcinoma ${ }^{34}$ and breast cancer cells ${ }^{35}$.

\section{Sphingosine kinase 2}

Two SPHK2 isoforms (SPHK2-S/SPHK2a and SPHK2-L/SPHK2b) have been identified, encoded by alternative start codon usage ${ }^{16}$. When compared with SPHK2a, SPHK2b possesses an additional 36 amino acids and is more abundantly expressed in a range of human tissues and cultured cells. Like SPHK1, SPHK2 displays intrinsic catalytic activity that can be further increased by ERK-1/2catalyzed phosphorylation on Ser 351 and/or Thr 578 (Ser 387 and Thr 614 on SPHK2b) ${ }^{36}$. SPHK2a localizes to either the nucleus or the cytoplasm and accumulates in the nucleus under conditions of stress ${ }^{16}$.

In the nucleus, SPHK2 produces S1P which binds to and inhibits HDAC 1/2 activity, resulting in increased histone acetylation and the subsequent expression of the cyclin-dependent kinase inhibitor $\mathrm{p} 21$, an inhibitor of cell cycle progression and the transcriptional regulator, c-Fos ${ }^{37}$. SPHK2 contains a NLS and a putative nuclear export signal (NES). Phosphorylation in the NES (either Ser 419 or Ser 421 of SPHK2b) by protein kinase D results in the export of SPHK2 from the nucleus into the cytoplasm ${ }^{38}$. SPHK2 can play a pro-apoptotic role when associated with the endoplasmic reticulum, by generating S1P which is channeled into biosynthesis of pro-apoptotic ceramide ${ }^{39}$. Further evidence to suggest a pro-apoptotic role for SPHK2 is the finding that the BH3-binding domain of SPHK2 sequesters and inhibits the pro-survival Bcl-2 family member, Bcl-xL ${ }^{40}$, while S1P formed by SPHK2 affects mitochondrial membrane permeability and cytochrome c release to induce apoptosis ${ }^{41}$.

However, several other more recent studies have suggested a pro-survival role for SPHK2 as its knock-down enhanced apoptosis and increased the sensitivity of cancer cells to chemotherapy ${ }^{42-45}$. This is supported by the finding that shRNA knock-down of SPHK2 in MCF7 human breast cancer cells results in delayed growth of cancer cells in immunocompromised mice ${ }^{46}$ 
Furthermore, the SPHK2 inhibitor ABC294640 decreased cell proliferation in a number of solid cancer types in vitro and induced autophagic cell death in kidney, prostate and breast tumor cell lines ${ }^{47-49}$ and inhibited in vivo growth of breast adenocarcinoma, hepatocellular and renal carcinoma $^{47,48}$. However, $\mathrm{ABC} 294640$ has since been found to inhibit and induce the proteasomal degradation of SPHK1 and dihydroceramide saturase ${ }^{50,51}$, which may contribute to its anti-tumor effects in vitro and in vivo.

\section{Sphingosine kinase inhibitors}

The advance in our understanding of the role of SPHKs in disease has provided impetus for the development of small molecule inhibitors of these enzymes. Selective inhibitors of SPHK1 with nanomolar potency include PF-543 ${ }^{52}$ and Genzyme compound $51^{53}$. These inhibitors are effective in a number of animal disease models. For instance, PF-543 decreases sickling of red blood cells in vitro and in vivo ${ }^{54}$ and reduces cardiac remodelling following post myocardial infarction where SPHK1/S1P/S1P participate in cardiac inflammation ${ }^{55}$. SPHK2-selective inhibitors include ABC294640, K145, SLR080811 and ROMe [(R)-FTY720-methyl-ether)], which exhibit micromolar potency. ABC294640 is in phase $1 / 2$ clinical trials for refractory/relapsed diffuse large B cell lymphoma (DLBCL) (NCT02229981) and multiple myeloma (MM) (NCT02757326). The use of SPHK2 inhibitors suggests a conserved role of SPHK2 in regulating common signalling pathways in different cancers. For instance, ROMe inhibits DNA synthesis in breast cancer cells ${ }^{56}$ and induces the autophagic death of leukemic T-ALL cell lines ${ }^{57}$. There are also inhibitors that target the ATPbinding site of SPHK. For instance, MP-A08 inhibits SPHK1 and SPHK2 with low micromolar potency ${ }^{29}$ and reduces cellular S1P levels, while elevating cellular ceramides, sphingosine, and dihydrosphingolipids. This appears to underlie the mechanisms by which MP-A08 induces apoptosis and inhibits cell proliferation and colony formation in vitro.

To date, there are no high-potency SPHK2-specific inhibitors. However, with the solved crystal structures of SPHK1 in the absence and presence of SPHK inhibitors (SKI-II ${ }^{58}$, PF-543 ${ }^{59}$ and 
Amgen compound $23{ }^{60}$ and with $\mathrm{ADP}^{58}$ ), it has been possible to define the sphingosine substrate binding site (named the 'J-channel' due to its shape), the nucleotide binding site and detail of the interaction of sphingosine-competitive inhibitors ${ }^{60}$ and an ATP-competitive inhibitor ${ }^{29}$. In the future this will help inform on the design of isoform-selective inhibitors by identifying and exploiting key differences between SPHK1 and SPHK2.

Dual SPHK1/SPHK2 inhibitors include SKI-II (also called SKi) ${ }^{61}$ and Amgen compound $82{ }^{62,63 .}$ SKI-II inhibits human SPHK1 and SPHK2 with micromolar potency ${ }^{63}$ and induces the proteasomal degradation of SPHK1 in cancer cells ${ }^{17}$. In vivo effects include the reduction of tumor volume ${ }^{64}$, reduced bronchial hyper-responsiveness, prevention of cerebral preconditioning and increased atherosclerosis in low-density lipoprotein receptor deficient $\left(\mathrm{LDL}-\mathrm{R}^{-/-}\right)$mice.

The therapeutic potential afforded by targeting SPHKs continues to fuel a drive to generate small molecule inhibitors for several disease indications.

\section{SPHINGOSINE METABOLISM AND SIGNALING IN MALIGNANT HEMATOPOIETIC}

\section{DISORDERS}

S1P displays well-known mitogenic and anti-apoptotic activities. Several factors [e.g. plateletderived growth factor (PDGF)] that promote proliferation/survival have been shown to activate SPHK1 in hematological malignancies such as T-cell large granular lymphocytic leukemia (T-LGL ${ }^{65}$ ). We will now review the evidence which links SPHKs and S1P with the pathobiology of malignant blood disorders (summarized in Table 1).

It should not be forgotten however, that S1P acts as a major chemoattractant which directs the egress of healthy hematopoietic stem cell from bone marrow ${ }^{66}$ as well as their homing and engraftment in the same compartment ${ }^{67}$. 


\section{Chronic myelogenous leukemia}

Some CML patients are either initially refractory to imatinib treatment or develop resistance and experience disease relapse. Second- and third-generation BCR/ABL1 inhibitors have been developed for treating imatinib-resistant patients and are being successfully used in the clinic ${ }^{68}$. However, even the introduction of these new drugs has not completely solved the problem of tyrosine kinase inhibitor resistance in CML patients as this leukemia can be driven independently of $\mathrm{BCR} / \mathrm{ABL} 1^{69}$.

Several lines of evidence support the possibility that SPHK1 and its regulation of the sphingolipid rheostat have an important role in CML. Baran et al. ${ }^{70}$ demonstrated that imatinib increased the generation of C18-ceramide in sensitive, but not resistant $\mathrm{K} 562$ cells $^{70}$. This was correlated with higher expression levels of SPHK1 in imatinib-resistant K562 cells. Indeed, the knock-down of SPHK1 expression by siRNA in these resistant cells decreased S1P levels and increased the sensitivity to imatinib, thereby providing evidence that SPHK1 was responsible for the acquisition of resistance to imatinib. This was supported by the finding that the overexpression of SPHK1 in K562 cells increased the total S1P/C18-ceramide level ratio approximately 6-fold and prevented apoptosis in response to imatinib. Interestingly, this is associated with a $\sim 2$-fold increase in BCR/ABL1 protein expression. A link between SPHK1 and BCR/ABL1 was evinced by the finding that the siRNA knock-down of SPHK1 resulted in a decrease in BCR/ABL1 protein levels ${ }^{70}$. This is important in terms of linking SPHK1 with clinical prognosis in CML as BCR/ABL1 levels are directly proportional to the extent of imatinib resistance in CML cell lines ${ }^{71-73}$ and in patients ${ }^{74}$.

Additional studies demonstrated that increased expression of SPHK1 in imatinib-resistant cells was due to over-activation of the PI3K/Akt/mTOR signaling pathway ${ }^{75}$. This was a significant finding as activation of this pathway has been linked with tyrosine kinase inhibitor resistance in CML cells $^{76-80}$. In addition, ERK-1/2 and Janus kinase (JAK) 2 are implicated in regulating the expression of SPHK1 in BCR/ABL1-transformed cells ${ }^{81}$. 
SPHK1/S1P signaling also enhances $\mathrm{BCR} / \mathrm{ABL} 1$ protein stability via a mechanism that involves $\mathrm{S}_{1} \mathrm{P}_{2}$-dependent inhibition of the proteasomal degradation of BCR/ABL1 in imatinib-resistant K562 and LAMA-4 human CML cells ${ }^{82}$. S1P binding to $\mathrm{S}_{1} \mathrm{P}_{2}$ prevented BCR/ABL1 dephosphorylation and degradation via inhibition of PP2A activity. Moreover, molecular or pharmacologic interference of SPHK1/S1P 2 signaling restored PP2A-dependent BCR/ABL1 dephosphorylation and enhanced imatinib- or nilotinib-induced growth inhibition in primary CD $34^{+}$mononuclear cells (obtained from either chronic phase or blast crisis CML patients), imatinib-resistant K562 or LAMA4 cells and 32Dcl3 murine progenitor cells, expressing the wild-type or mutant (Y253H or T315I) BCR/ABL1. This model was supported by evidence demonstrating that the abrogation of SPHK1/S1P 2 signaling enhanced the growth-inhibitory effects of nilotinib in 32D/T315I-BCRABL1-derived mouse allografts ${ }^{82}$.

These findings support the notion that inhibiting SPHK1/S1P $\mathrm{P}_{2}$ signaling might represent a novel approach for targeting either wild-type or mutant BCR/ABL1, thereby overcoming resistance to tyrosine kinase inhibitors in CML cells. In this regard, treatment with the SPHK1 inhibitor, SKI-II, impaired cell cycle progression and induced apoptosis in K562 cells. Moreover, SKI-II acted synergistically with imatinib to inhibit cell growth and survival and affected the clonogenic potential and viability of primary cells from CML patients, including one patient harboring the imatinib-insensitive T315I mutation ${ }^{83}$. The anti-apoptotic activity of SPHK1 in BCR/ABL1harboring CML cells is dependent on the expression of Bcl-2 family members. Thus, imatinib treatment failed to down-regulate anti-apoptotic Bcl-xL and myeloid cell leukemia-1 (Mcl-1) levels in LAMA84 cells overexpressing SPHK1, as well as increasing the expression of pro-apoptotic Bim in LAMA84/Neo cells ${ }^{84}$. Mcl-1 appears to have a critical role in mediating the anti-apoptotic function of SPHK1. This was evidenced by studies showing that combined treatment of K562 and primary cells from CML patients with SKI-II and the proteosomal inhibitor bortezomib caused apoptosis accompanied by down-regulation of Mcl-1 ${ }^{85}$. A schematic on the relationship between SPHK1/S1P, BCR/ABL1 and imatinib resistance is presented in Figure 3. 
These findings provide a powerful rationale for targeting SPHK1 in CML, not least because the overwhelming evidence suggests that SPHK1 has a critical and definitive role in regulating the oncogenic signaling gain of $\mathrm{BCR} / \mathrm{ABL} 1$ through an $\mathrm{S} 1 \mathrm{P} / \mathrm{S} 1 \mathrm{P}_{2}$ receptor-dependent stabilization of BCR/ABL1. In addition, SPHK1 also confers resistance of CML cells to imatinib by maintaining Mcl-1 expression. Taken together these findings demonstrate functional association of SPHK1 with important oncogenes that underlie the hallmarks of cancer.

\section{Large granular lymphocytic leukemia}

LGL leukemia is a rare and incurable chronic disease, characterized by clonal expansion of either cytotoxic T-cells (T-LGL) or natural killer (NK) cells (NK-LGL) in blood and bone marrow. Somatic activating Signal Transducer and Activator of Transcription (STAT) 3 mutations have been shown to be specific for T-LGL leukemia and with a prevalence of up to $70 \%{ }^{86}$. It has been shown that SPHK1 is activated by PDGF in T-LGL and its inhibition by SKI-I and SKI-II can significantly induce apoptosis of leukemic cells ${ }^{65}$. The importance of this finding is exemplified by the fact that SPHK1 is overexpressed in NK-LGL cells. Moreover, the mechanism by which SKI-II or SKI-178 induce apoptosis in NK-LGL cells is associated with increased ceramide and decreased S1P levels, consistent with inhibition of SPHK1 and in line with the predicted outcome of modulating the sphingolipid rheostat. Significantly, the apoptotic effect of SPHK1 inhibitors in NK-LGL cells was linked with decreased oncogenic JAK/STAT signaling ${ }^{87}$.

\section{Acute lymphoblastic leukemia}

The prognosis for pediatric B-ALL and T-ALL patients has dramatically improved over the last two decades with survival rates of approximately $75-80 \%$ at 5 -years. In contrast, the outcome of adult patients is much more severe ${ }^{88}$. Therefore, novel targeted therapies for treatment of B- and T-ALL are required, especially for adult cases. 
It was recently shown that SPHK2 has a significant role in B-ALL by regulating the expression of c-MYC. This was based on the finding that genetic ablation of SPHK2 impaired leukemogenesis in a mouse model of B-ALL and pharmacologic inhibition with ABC294640 prolonged survival in mouse xenograft models of human disease ${ }^{89}$. Indeed, inhibition of SPHK2 reduced c-MYC expression in these leukemic cells and was associated with decreased acetylated K9 histone H3 levels within the c-MYC gene promoter and reduced c-MYC-regulated gene expression. These findings have provided preclinical proof-of-concept for targeting SPHK2/c-MYC as a broad-based therapeutic approach in B-ALL.

S1P prevents T-ALL Jurkat cell apoptosis induced by anti-Fas, TNF- $\alpha$, serum deprivation and cellpermeable ceramides. This is associated with reduced caspase- 3 activation, a consequence of inhibiting the release of cytochrome $\mathrm{c}$ and Smac/DIABLO from mitochondria ${ }^{90}$. Recently, we have shown that the SPHK1/2 inhibitor SKI-II ${ }^{61}$ induced apoptosis of T-ALL cells, while the SPHK2selective inhibitor ROMe ${ }^{56}$ induced autophagic death of these cells ${ }^{57}$. SKI-II treatment induced an increase in SPHK1 protein levels in MOLT-4 cells, whereas it activated the ER stress/unfolded protein response (UPR) pathway in Jurkat and CEM-R cells as protective mechanisms in a subpopulation of T-ALL cells ${ }^{57}$. Interestingly, we observed a synergistic effect of SKI-II with the classical chemotherapeutic drug, vincristine. In addition, we reported that SKI-II affected signaling pathways implicated in survival, proliferation, and stress response of T-ALL cells. These findings indicate that SPHK1 and/or SPHK2 are potential therapeutic targets for treating T-ALL ${ }^{57}$.

The overwhelming evidence suggests that SPHK1 and SPHK2 have a critical role in regulating the expression and function of the oncogene c-MYC, which is the master transcriptional regulator of glycolytic gene products essential for the Warburg effect and to which cancer cells are addicted for production of ATP and biosynthetic intermediates ${ }^{91}$. The functional link between SPHKs and cMYC provides a strong rationale for targeting these enzymes in both T-ALL and B-ALL. 


\section{Acute myelogenous leukemia}

362 AML is a clonal disorder characterized by pronounced clinical and biological heterogeneity.

363

364

365

Despite considerable advances in our understanding of pathogenesis, genomic alterations and prognostic factors, AML treatment has changed little in the last 40 years and the prognostic outcome remains poor for the majority of patients ${ }^{92}$. Over the last 10 years, there have been an increasing number of signaling pathways identified for targeting with new drugs in AML.

Studies on S1P and AML have shown that this bioactive lipid mobilizes intracellular $\mathrm{Ca}^{2+}$ in U937 cells and activates NF- $\mathrm{KB}^{93}$ and is capable of inhibiting apoptosis in both U937 and HL-60 cells ${ }^{90}$. Importantly, several studies have identified SPHK1 as a potential drug target for AML treatment. For instance, BML-258 (SKI-I) is a micromolar potency, water-soluble, SPHK1 inhibitor and has been shown to decrease growth and survival of human AML U937 cells. This is associated with an increased ceramide : S1P ratio, cleavage of Bcl-2 and apoptosis ${ }^{27}$. Indeed, the pro-apoptotic effect of BML-258 was reversed by caspase inhibitors and by overexpression of Bcl-2. BML-258 also abrogates survival signaling pathways, including ERK-1/2 and Akt. The importance of these pathways in the apoptotic activity of BML-258 was demonstrated by the finding that overexpression of constitutively active Akt protected against BML-258-induced apoptosis. Importantly, BML-258 potently induced apoptosis in leukemic blasts isolated from patients with AML but was relatively sparing of peripheral blood mononuclear leukocytes from healthy donors. Moreover, BML-258 markedly reduced growth of AML xenograft tumors. These results suggested that SPHK1 inhibitors warrant attention as potential additions to the therapeutic arsenal in AML ${ }^{27}$. Subsequent studies have confirmed this conclusion, using inhibitors such as SKI-178 ${ }^{94}$ and SKI-II 95.

SPHK1 activity has also been linked to multidrug-resistant (MDR) phenotype in AML HL-60 cells 96. In this regard, treatment of chemosensitive HL-60 cells with either doxorubicin and etoposide produced a marked decrease in SPHK1 activity and an acute generation (around 50\% increase) of the pro-apoptotic ceramide. However, doxorubicin and etoposide failed to induce apotosis of 
chemoresistant HL-60/doxorubicin and HL-60/etoposide cells which overexpress MRP1 (ABCC1) and MDR1 (ABCB1), respectively. This difference in chemosensitivity can be explained by the finding that chemoresistant HL-60/doxorubicin and HL-60/etoposide cells express higher levels of SPHK1 activity and therefore are resistant to changes in ceramide levels upon treatment with these apoptotic agents. The mechanism by which SPHK1 is protective against apoptosis is linked with a reduction in ceramide levels and inhibition of mitochondrial cytochrome c efflux. Indeed, treatment of chemoresistant cells with cell-permeable ceramide led to SPHK1 inhibition and the induction of apoptosis, both of which were prevented by over-expression of SPHK1. More effective SPHK1 inhibitors might overcome the chemoresistance in AML. Indeed, the SPHK inhibitor, F-12509a increased the ceramide:S1P ratio and promoted apoptosis of both chemosensitive and chemoresistant AML cell lines with equal sensitivity ${ }^{96}$.

Taken together, the evidence suggests that the regulation of the intrinsic apoptotic pathway in AML by SPHK1 and in particular the inhibition of the proteolytic processing of the oncogene, Bcl-2 is a critical component in promoting AML cell survival and chemoresistance. This therefore serves as another example of the important role that SPHK1 plays in augmenting oncogene function in hematological cancers.

\section{Non-Hodgkin lymphomas}

The outcome for patients with NHL has improved substantially over the past four decades. However, there remain NHL subtypes with a very poor prognosis. Interestingly, SPHK1 protein and mRNA levels were higher in 44 NHL patients than in controls (25 individuals with reactive lymphoid hyperplasia) and there was a clear trend toward increasing SPHK1 mRNA levels and clinical grade in this cancer ${ }^{25}$.

Mantle cell lymphoma (MCL) is a distinct subset of B-cell non-Hodgkin lymphoma (NHL) characterized by the $\mathrm{t}(11 ; 14)(\mathrm{q} 13 ; \mathrm{q} 32)$ chromosomal translocation and which results in overexpression of cyclin D1 and deregulation of the cell cycle ${ }^{97}$. Although intensive 
polychemotherapy schemes and immunotherapy with anti-CD20 monoclonal antibody (Rituximab) have improved the outcome of patients with $\mathrm{MCL}^{98}$, no standard of care is currently available for this cancer which remains incurable ${ }^{99}$. Several signal transduction pathways are aberrantly activated in MCL, including NF- $\mathrm{KB}, \mathrm{PI} 3 \mathrm{~K} / \mathrm{Akt} / \mathrm{mTOR}$ and JAK3/STAT3 ${ }^{100}$. In addition, $\mathrm{S}_{1} \mathrm{P}_{1}$ expression levels are elevated in MCL. In particular, this receptor was strongly expressed on the surface of small lymphocytes forming primary lymphoid follicles and in the mantle zone of secondary lymphoid follicles ${ }^{101}$. Interestingly, FTY720 (fingolimod, a pro-drug and functional antagonist of ${\mathrm{S} 1 \mathrm{P}_{1}}_{1}$ used in the treatment of relapsing and remittent multiple sclerosis ${ }^{102}$ ) induced the caspase-independent death of primary MCL tumor cells and MCL cell lines in vitro. Moreover, FTY720 treatment resulted in the down-regulation of cyclin D1 and this was accompanied by an accumulation of cells in $\mathrm{G}_{0}-\mathrm{G}_{1}$ and $\mathrm{G}_{2}-\mathrm{M}$ phases of the cell cycle with a concomitant decrease in Sphase entry. In addition, cytotoxicity was associated with a decrease in phosphorylated Akt levels. Most importantly, the in vivo therapeutic efficacy of FTY720 was demonstrated in mice xenografted with Jeko human MCL cell line ${ }^{103}$. These effects of FTY720 are likely mediated by its inhibition of SPHK $1{ }^{104}$ or activation of PP2A ${ }^{105}$.

Overexpression of $\mathrm{S}_{2} \mathrm{P}_{2}$ was recently reported in several types of NHL, including follicular lymphoma (FL), DLBCL, MCL and marginal-zone lymphoma (MZL) ${ }^{106}$. One of the most aggressive subtypes of NHL is activated B cell-like DLBCL (ABC-DLBCL). This cancer remains a challenge for effective therapy ${ }^{107}$. In this regard, STAT3 is known to be activated in ABC-DLBCL cells and might be of significant clinical importance in terms of disease progression ${ }^{108}$. Intriguingly, $\mathrm{S}_{1} \mathrm{P}_{1}$ can activate STAT3 through JAK2 ${ }^{109}$ and some ABC-DLBCL patients exhibit elevated S1P and activated STAT3 levels. The importance of this finding was exemplified by the finding that treatment with ${\mathrm{S} 1 \mathrm{P}_{1}}_{1}$ shRNA or FTY720 down-regulated STAT3 activity and caused tumor growth inhibition in xenografts or syngeneic mouse models of lymphoma ${ }^{110}$ (Figure 4). Moreover, the overexpression of $\mathrm{S}_{1} \mathrm{P}_{1}$ and high levels of phosphorylated STAT3 are associated with poor prognosis in rituximab-treated DLBCL ${ }^{111}$. Very recently, it has been documented that $\mathrm{S}_{1} \mathrm{P}_{1}$ is 
overexpressed in $54.2 \%$ of 24 cases with primary testicular DLBCL and $\mathrm{S}_{1} \mathrm{P}_{1}$ levels correlated with STAT3 phosphorylation ${ }^{112}$.

Another rare and extremely aggressive variant of DLBCL is primary effusion lymphoma (PEL), a human herpes virus 8 (HHV8)-positive neoplasm that presents as an effusion within pleural or peritoneal cavities with no detectable tumor in individuals with human immunodeficiency virus infection or other immune deficiencies. In most cases, PEL cells also harbor the Epstein-Barr virus (EBV) genome ${ }^{113}$. PEL progresses rapidly despite chemotherapy, with a median survival of around 6 months ${ }^{114}$. It has been reported that ABC294640 induced dose-dependent caspase cleavage and apoptosis in $\mathrm{HHV}^{+}$patient-derived PEL cells, thereby implicating a role for SPHK2 in this cancer. Also, ABC294640 down-regulated signaling pathways that are known for being activated in PEL and which are regulated by S1P, including MEK-ERK-1/2, PI3K/Akt/mTOR and NF- $\mathrm{BB}^{115}$. The role of SPHK2 was validated by induction of PEL cell apoptosis using SPHK2-specific siRNA. In addition, pharmacological inhibition of SPHK1 in PEL cells was associated with a dose-dependent accumulation of pro-apoptotic ceramide and a reduction of intracellular S1P. Finally, in vivo administration of ABC294640 induces tumor regression in an established human PEL xenograft model ${ }^{115}$. Sequential Phase 1 and 2a trials are on-going to identify the maximum tolerated dose and to evaluate safety, tolerability, toxicity, pharmacokinetics and pharmacodynamics of ABC294640 in patients with PEL (NCT02229981).

Taken together the data support a major role for both SPHK1 and SPHK2 and S1P receptor signaling systems in NHL, particularly with respect to the regulation of oncogenic JAK/STAT and Akt pro-survival functions. This might involve signaling loops involving SPHK1 and S1P that are subsequently released to act in an autocrine or paracrine manner to promote $\mathrm{S}_{1} \mathrm{P}_{1}$ receptordependent JAK/STAT regulation of NHL growth. 


\section{Multiple myeloma}

466 New classes of therapeutic agents have displayed remarkable efficacy in MM patients. 467 Nevertheless, novel therapeutic approaches are still urgently needed to further improve patient outcome. The bone marrow microenvironment (e.g. stromal cells and immune cells) plays a central role in MM pathogenesis, by promoting tumor cell growth, survival and chemo-resistance ${ }^{116}$. A possible involvement of SPHKs in MM cell survival and chemo-resistance was first highlighted 10 years ago when it was shown that FTY720 was cytotoxic against both drug-sensitive and drugresistant MM cell lines. This was also demonstrated in isolated tumor cells from MM patients who did not respond to conventional agents ${ }^{117}$. In this regard, FTY720 has been shown to induce caspase activation and poly(ADP-ribose) polymerase (PARP) cleavage. Importantly, FYT720 retained its cytotoxicity even in the presence of interleukin-6 (IL-6) or insulin-like growth factor-1 (IGF-1). It should be noted that IL-6 and IGF-1 are two of the most important cytokines, released by the bone marrow microenvironment, that support growth and survival of MM cells ${ }^{118}$. Importantly, growth of MM cells adherent to bone marrow stromal cells was significantly inhibited by FTY720 and this was associated with down-regulation of signaling pathways critical for MM pathobiology, including PI3K/Akt/mTOR, MEK/ERK-1/2, STAT3 and NK-אB ${ }^{117}$.

Recent findings have highlighted that SPHK1 protein expression is elevated in MM cells and its inhibition resulted in apoptotic death of cancer cells due to the prevention of receptor tyrosine kinase phosphorylation and activation of death-associated protein kinase 1 (DAPK1) ${ }^{119}$.

S1P might also play an important role in MM cell adhesion, which is dependent on $\alpha 4 \beta 1$ integrin and is crucial for the progression of the disease ${ }^{120}$. In this context, $\alpha 4 \beta 1$-dependent MM cell adhesion is up-regulated by the chemokine, CXCL12 ${ }^{121}$. S1P enhances $\alpha 4 \beta 1$-mediated MM cell adhesion and transendothelial migration stimulated by CXCL12 ${ }^{122}$. In particular, S1P promotes the generation of high-affinity $\alpha 4 \beta 1$ that efficiently binds $\alpha 4 \beta 1$ ligand and vascular cell adhesion molecule 1 (VCAM-1). Importantly, this is associated with an S1P-induced increase in talin- $\beta 1$ integrin association. Furthermore, S1P cooperates with CXCL12 in enhancing $\alpha 4 \beta 1$-dependent 
adhesion and spreading. The mechanism of this cooperation involves activation of the dedicator of cytokinesis 2 (DOCK2)-Rac1 pathway which is required for stimulation of MM cell adhesion via $\alpha 4 \beta 1$. The pathophysiological significance of these findings is evident from in vivo studies, which have demonstrated that S1P contributed to optimizing the interactions of MM cells with the bone marrow microvasculature and for their lodging inside the bone marrow ${ }^{122}$.

More recently, SPHK2 has been found to be overexpressed in MM cell lines and in primary human bone marrow MM cells ${ }^{123}$. Down-regulation of SPHK2 by shRNA or treatment with ABC294640 inhibited proliferation and induced caspase 3-mediated apoptosis in both MM cell lines and primary cells and this can be achieved even in the presence of bone marrow stromal cells. Furthermore, ABC294640 directed c-MYC and Mcl-1 for proteasome degradation and increased pro-apoptotic Noxa gene transcription and protein expression and suppressed the growth of human MM.1S cells in a mouse xenograft cancer model ${ }^{123}$.

Overall, these findings have provided the preclinical framework for clinical trials of SPHK inhibitors, used alone and/or combined with conventional and novel therapies to improve patient outcome in MM.

\section{Conclusions and future perspectives}

Over the last five years there have been major advances in understanding the role of S1P and SPHKs in hematological malignancies. Aberrant regulation of the sphingolipid metabolism is involved in the progression of malignancy and cancer cell drug-resistance. Therefore, a promising approach for targeted treatment of hematological malignancies is the development of SPHK inhibitors that increase pro-apoptotic sphingolipids such as ceramides while suppressing the synthesis of the anti-apoptotic S1P.

Suppression of SPHK1 by genetic ablation (siRNA or gene knockout murine models) or chemical inhibition have established the important role of this enzyme in cancer. Although our knowledge of SPHK2 is more limited, the burgeoning evidence also suggests a role in cancer. Therefore, highly 
selective and potent SPHK2 inhibitors are eagerly awaited in order to provide a means for a more thorough interrogation of this enzyme in hematological cancers. SPHK1 and SPHK2 may not be the only relevant targets in cancer cells as the pathways regulating these enzymes and down-stream targets are also worthy of therapeutic targeting. The simultaneous inhibition of both SPHK1 and SPHK2 activity also warrants appraisal ${ }^{5}$.

Finally, the potential for combining SPHK inhibitors (or other sphingolipid pathway components deregulated in cancer) with currently available therapeutic agents (either targeted or classic chemotherapeutic drugs) holds significant promise for improved disease-treatment outcome. However, the reported combinatory effects are scarce at present. One notable exception concerns CML. In this regard, there are impressive findings concerning the re-sensitization of imatinibresistant CML cells by inhibiting SPHK1 activity ${ }^{5}$. It is in this disorder that the greatest translational advances will most likely be made. However, it is clear that better and more selective and potent SPHK inhibitors are required for the translation to the clinic. These compounds are already under development and it is hoped they will be tested in clinical trials in the near future.

\section{Conflict of Interest}

The authors declare no conflict of interest.

\section{References}

1. Jabbour E, Kantarjian H, Cortes J. Use of Second- and Third-Generation Tyrosine Kinase Inhibitors in the Treatment of Chronic Myeloid Leukemia: An Evolving Treatment Paradigm. Clin Lymphoma, Myeloma Leuk 2015; 15: 323-334.

2. Pyne S, Chapman J, Steele L, Pyne NJ. Sphingomyelin-derived lipids differentially regulate the extracellular signal-regulated kinase 2 (ERK-2) and c-Jun N-terminal kinase (JNK) signal cascades in airway smooth muscle. Eur J Biochem 1996; 237: 819-826.

3. Cuvillier O, Pirianov G, Kleuser B, Vanek PG, Coso OA, Gutkind S, et al. Suppression of ceramide-mediated programmed cell death by sphingosine-1-phosphate. Nature 1996; 381: 800-803. 
4. $\quad$ Pyne NJ, Pyne S. Sphingosine 1-phosphate and cancer. Nat Rev Cancer 2010; 10: 489-503.

5. Wallington-Beddoe CT, Bradstock KF, Bendall LJ. Oncogenic properties of sphingosine kinases in haematological malignancies. Br J Haematol 2013; 161: 623-638.

6. Pyne S, Adams DR, Pyne NJ. Sphingosine 1-phosphate and sphingosine kinases in health and disease: Recent advances. Prog Lipid Res 2016; 62: 93-106.

7. Nishi T, Kobayashi N, Hisano Y, Kawahara A, Yamaguchi A. Molecular and physiological functions of sphingosine 1-phosphate transporters. Biochim Biophys Acta 2014; 1841: 759765 .

8. Xu Y, Xiao YJ, Baudhuin LM, Schwartz BM. The role and clinical applications of bioactive lysolipids in ovarian cancer. J Soc Gynecol Invest 2001; 8: 1-13.

9. Sutphen R, Xu Y, Wilbanks GD, Fiorica J, Grendys EC, Jr., LaPolla JP, et al. Lysophospholipids are potential biomarkers of ovarian cancer. Cancer Epidemiol Biomarkers Prev 2004; 13: 1185-1191.

10. Long JS, Fujiwara Y, Edwards J, Tannahill CL, Tigyi G, Pyne S, et al. Sphingosine 1phosphate receptor 4 uses HER2 (ERBB2) to regulate extracellular signal regulated kinase1/2 in MDA-MB-453 breast cancer cells. J Biol Chem 2010; 285: 35957-35966.

11. Shida D, Fang X, Kordula T, Takabe K, Lepine S, Alvarez SE, et al. Cross-talk between LPA1 and epidermal growth factor receptors mediates up-regulation of sphingosine kinase 1 to promote gastric cancer cell motility and invasion. Cancer Res 2008; 68: 6569-6577.

12. Pyne NJ, Pyne S. Receptor tyrosine kinase-G-protein-coupled receptor signalling platforms: out of the shadow? Trends Pharmacol Sci 2011; 32: 443-450.

13. Long JS, Edwards J, Watson C, Tovey S, Mair KM, Schiff R, et al. Sphingosine kinase 1 induces tolerance to human epidermal growth factor receptor 2 and prevents formation of a migratory phenotype in response to sphingosine 1-phosphate in estrogen receptor-positive breast cancer cells. Mol Cell Biol 2010; 30: 3827-3841.

14. Watson C, Long JS, Orange C, Tannahill CL, Mallon E, McGlynn LM, et al. High expression of sphingosine 1-phosphate receptors, S1P1 and S1P3, sphingosine kinase 1, and extracellular signal-regulated kinase- $1 / 2$ is associated with development of tamoxifen resistance in estrogen receptor-positive breast cancer patients. Am J Pathol 2010; 177: 22052215 . 
15. Pitson SM. Regulation of sphingosine kinase and sphingolipid signaling. Trends Biochem Sci 2011; 36: 97-107.

16. Neubauer HA, Pitson SM. Roles, regulation and inhibitors of sphingosine kinase 2. FEBS $J$ 2013; 280: 5317-5336.

17. Loveridge C, Tonelli F, Leclercq T, Lim KG, Long JS, Berdyshev E, et al. The sphingosine kinase 1 inhibitor 2-(p-hydroxyanilino)-4-(p-chlorophenyl)thiazole induces proteasomal degradation of sphingosine kinase 1 in mammalian cells. J Biol Chem 2010; 285: 3884138852 .

18. Pitson SM, Moretti PA, Zebol JR, Xia P, Gamble JR, Vadas MA, et al. Expression of a catalytically inactive sphingosine kinase mutant blocks agonist-induced sphingosine kinase activation. A dominant-negative sphingosine kinase. J Biol Chem 2000; 275: 33945-33950.

19. Pitson SM, Moretti PA, Zebol JR, Lynn HE, Xia P, Vadas MA, et al. Activation of sphingosine kinase 1 by ERK1/2-mediated phosphorylation. EMBO J 2003; 22: 5491-5500.

20. Jarman KE, Moretti PA, Zebol JR, Pitson SM. Translocation of sphingosine kinase 1 to the plasma membrane is mediated by calcium- and integrin-binding protein 1 . J Biol Chem 2010; 285: 483-492.

21. Barr RK, Lynn HE, Moretti PA, Khew-Goodall Y, Pitson SM. Deactivation of sphingosine kinase 1 by protein phosphatase 2A. J Biol Chem 2008; 283: 34994-35002.

22. Takabe K, Paugh SW, Milstien S, Spiegel S. "Inside-out" signaling of sphingosine-1phosphate: therapeutic targets. Pharmacol Rev 2008; 60: 181-195.

23. Vadas M, Xia P, McCaughan G, Gamble J. The role of sphingosine kinase 1 in cancer: oncogene or non-oncogene addiction? Biochim Biophys Acta 2008; 1781: 442-447.

24. Sobue S, Nemoto S, Murakami M, Ito H, Kimura A, Gao S, et al. Implications of sphingosine kinase 1 expression level for the cellular sphingolipid rheostat: relevance as a marker for daunorubicin sensitivity of leukemia cells. Int J Hematol 2008; 87: 266-275.

25. Bayerl MG, Bruggeman RD, Conroy EJ, Hengst JA, King TS, Jimenez M, et al. Sphingosine kinase 1 protein and mRNA are overexpressed in non-Hodgkin lymphomas and are attractive targets for novel pharmacological interventions. Leuk Lymphoma 2008; 49: 948-954.

26. Zhang Y, Wang Y, Wan Z, Liu S, Cao Y, Zeng Z. Sphingosine kinase 1 and cancer: a systematic review and meta-analysis. PloS One 2014; 9: e90362. 
642

643

644

645

646

647

648

649

650

651

652

653

654

655

656

657

658

659

660

661

662

663

664

665

666

667

668

669

670

671

672
27. Paugh SW, Paugh BS, Rahmani M, Kapitonov D, Almenara JA, Kordula T, et al. A selective sphingosine kinase 1 inhibitor integrates multiple molecular therapeutic targets in human leukemia. Blood 2008; 112: 1382-1391.

28. Datta A, Loo SY, Huang B, Wong L, Tan SS, Tan TZ, et al. SPHK1 regulates proliferation and survival responses in triple-negative breast cancer. Oncotarget 2014; 5: 5920-5933.

29. Pitman MR, Powell JA, Coolen C, Moretti PA, Zebol JR, Pham DH, et al. A selective ATPcompetitive sphingosine kinase inhibitor demonstrates anti-cancer properties. Oncotarget 2015; 6: 7065-7083.

30. Lee JW, Ryu JY, Yoon G, Jeon HK, Cho YJ, Choi JJ, et al. Sphingosine kinase 1 as a potential therapeutic target in epithelial ovarian cancer. Int J Cancer 2015; 137: 221-229.

31. Pchejetski D, Doumerc N, Golzio M, Naymark M, Teissie J, Kohama $\mathrm{T}$, et al. Chemosensitizing effects of sphingosine kinase-1 inhibition in prostate cancer cell and animal models. Mol Cancer Ther 2008; 7: 1836-1845.

32. Sauer L, Nunes J, Salunkhe V, Skalska L, Kohama T, Cuvillier O, et al. Sphingosine kinase 1 inhibition sensitizes hormone-resistant prostate cancer to docetaxel. int J Cancer 2009; 125: $2728-2736$.

33. Pchejetski D, Bohler T, Brizuela L, Sauer L, Doumerc N, Golzio M, et al. FTY720 (fingolimod) sensitizes prostate cancer cells to radiotherapy by inhibition of sphingosine kinase-1. Cancer Res 2010; 70: 8651-8661.

34. Guillermet-Guibert J, Davenne L, Pchejetski D, Saint-Laurent N, Brizuela L, GuilbeauFrugier $\mathrm{C}$, et al. Targeting the sphingolipid metabolism to defeat pancreatic cancer cell resistance to the chemotherapeutic gemcitabine drug. Mol Cancer Ther 2009; 8: 809-820.

35. Sukocheva O, Wang L, Verrier E, Vadas MA, Xia P. Restoring endocrine response in breast cancer cells by inhibition of the sphingosine kinase-1 signaling pathway. Endocrinology 2009; 150: 4484-4492.

36. Hait NC, Bellamy A, Milstien S, Kordula T, Spiegel S. Sphingosine kinase type 2 activation by ERK-mediated phosphorylation. J Biol Chem 2007; 282: 12058-12065.

37. Hait NC, Allegood J, Maceyka M, Strub GM, Harikumar KB, Singh SK, et al. Regulation of histone acetylation in the nucleus by sphingosine-1-phosphate. Science 2009; 325: 12541257. 
38. Ding G, Sonoda H, Yu H, Kajimoto T, Goparaju SK, Jahangeer S, et al. Protein kinase Dmediated phosphorylation and nuclear export of sphingosine kinase 2. J Biol Chem 2007; 282: 27493-27502.

39. Maceyka M, Sankala H, Hait NC, Le Stunff H, Liu H, Toman R, et al. SphK1 and SphK2, sphingosine kinase isoenzymes with opposing functions in sphingolipid metabolism. $J$ Biol Chem 2005; 280: 37118-37129.

40. Liu H, Toman RE, Goparaju SK, Maceyka M, Nava VE, Sankala H, et al. Sphingosine kinase type 2 is a putative BH3-only protein that induces apoptosis. $J$ Biol Chem 2003; 278: 40330-40336.

41. Chipuk JE, McStay GP, Bharti A, Kuwana T, Clarke CJ, Siskind LJ, et al. Sphingolipid metabolism cooperates with BAK and BAX to promote the mitochondrial pathway of apoptosis. Cell 2012; 148: 988-1000.

42. Van Brocklyn JR, Jackson CA, Pearl DK, Kotur MS, Snyder PJ, Prior TW. Sphingosine kinase-1 expression correlates with poor survival of patients with glioblastoma multiforme: roles of sphingosine kinase isoforms in growth of glioblastoma cell lines. J Neuropathol Exp Neurol 2005; 64: 695-705.

43. Sankala HM, Hait NC, Paugh SW, Shida D, Lepine S, Elmore LW, et al. Involvement of sphingosine kinase 2 in p53-independent induction of p21 by the chemotherapeutic drug doxorubicin. Cancer Res 2007; 67: 10466-10474.

44. Nemoto S, Nakamura M, Osawa Y, Kono S, Itoh Y, Okano Y, et al. Sphingosine kinase isoforms regulate oxaliplatin sensitivity of human colon cancer cells through ceramide accumulation and Akt activation. J Biol Chem 2009; 284: 10422-10432.

45. Schnitzer SE, Weigert A, Zhou J, Brune B. Hypoxia enhances sphingosine kinase 2 activity and provokes sphingosine-1-phosphate-mediated chemoresistance in A549 lung cancer cells. Mol Cancer Res 2009; 7: 393-401.

46. Weigert A, Schiffmann S, Sekar D, Ley S, Menrad H, Werno C, et al. Sphingosine kinase 2 deficient tumor xenografts show impaired growth and fail to polarize macrophages towards an anti-inflammatory phenotype. Int J Cancer 2009; 125: 2114-2121.

47. Beljanski V, Knaak C, Smith CD. A novel sphingosine kinase inhibitor induces autophagy in tumor cells. J Pharmacol Exp Ther 2010; 333: 454-464.

48. French KJ, Zhuang Y, Maines LW, Gao P, Wang W, Beljanski V, et al. Pharmacology and antitumor activity of ABC294640, a selective inhibitor of sphingosine kinase-2. J Pharmacol Exp Ther 2010; 333: 129-139. 
49. Beljanski V, Lewis CS, Smith CD. Antitumor activity of sphingosine kinase 2 inhibitor ABC294640 and sorafenib in hepatocellular carcinoma xenografts. Cancer Biol Ther 2011; 11: 524-534.

50. McNaughton M, Pitman M, Pitson SM, Pyne NJ, Pyne S. Proteasomal degradation of sphingosine kinase 1 and inhibition of dihydroceramide desaturase by the sphingosine kinase inhibitors, SKi or ABC294640, induces growth arrest in androgen-independent LNCaP-AI prostate cancer cells. Oncotarget 2016; 7:16663-16675.

51. Venant H, Rahmaniyan M, Jones EE, Lu P, Lilly MB, Garrett-Mayer E, et al. The Sphingosine Kinase 2 Inhibitor ABC294640 Reduces the Growth of Prostate Cancer Cells and Results in Accumulation of Dihydroceramides In Vitro and In Vivo. Mol Cancer Ther 2015; 14: 2744-2752.

52. Schnute ME, McReynolds MD, Kasten T, Yates M, Jerome G, Rains JW, et al. Modulation of cellular S1P levels with a novel, potent and specific inhibitor of sphingosine kinase-1. Biochem J 2012; 444: 79-88.

53. Xiang Y, Hirth B, Kane JL, Jr., Liao J, Noson KD, Yee C, et al. Discovery of novel sphingosine kinase-1 inhibitors. Part 2. Bioorg Med Chem Lett 2010; 20: 4550-4554.

54. Zhang Y, Berka V, Song A, Sun K, Wang W, Zhang W, et al. Elevated sphingosine-1phosphate promotes sickling and sickle cell disease progression. $J$ Clin Invest 2014; 124: 2750-2761.

55. Zhang F, Xia Y, Yan W, Zhang H, Zhou F, Zhao S, et al. Sphingosine 1-phosphate signaling contributes to cardiac inflammation, dysfunction, and remodeling following myocardial infarction. Am J Physiol Heart Circ Physiol 2016; 310: H250-261.

56. Lim KG, Sun C, Bittman R, Pyne NJ, Pyne S. (R)-FTY720 methyl ether is a specific sphingosine kinase 2 inhibitor: Effect on sphingosine kinase 2 expression in HEK 293 cells and actin rearrangement and survival of MCF-7 breast cancer cells. Cell Signal 2011; 23: 1590-1595.

57. Evangelisti C, Teti G, Chiarini F, Falconi M, Melchionda F, Pession A, et al. Assessment of the effect of sphingosine kinase inhibitors on apoptosis, unfolded protein response and autophagy of T-cell acute lymphoblastic leukemia cells; indications for novel therapeutics. Oncotarget 2014; 5: 7886-7901.

58. Wang Z, Min X, Xiao SH, Johnstone S, Romanow W, Meininger D, et al. Molecular basis of sphingosine kinase 1 substrate recognition and catalysis. Structure 2013; 21: 798-809. 
59. Wang J, Knapp S, Pyne NJ, Pyne S, Elkins JM. Crystal Structure of Sphingosine Kinase 1 with PF-543. ACS Med Chem Lett 2014; 5: 1329-1333.

60. Gustin DJ, Li Y, Brown ML, Min X, Schmitt MJ, Wanska M, et al. Structure guided design of a series of sphingosine kinase (SphK) inhibitors. Bioorg Med Chem Lett 2013; 23: 46084616.

61. French KJ, Schrecengost RS, Lee BD, Zhuang Y, Smith SN, Eberly JL, et al. Discovery and evaluation of inhibitors of human sphingosine kinase. Cancer Res 2003; 63: 5962-5969.

62. Santos WL, Lynch KR. Drugging sphingosine kinases. ACS Chem Biol 2015; 10: 225-233.

63. Rex K, Jeffries S, Brown ML, Carlson T, Coxon A, Fajardo F, et al. Sphingosine kinase activity is not required for tumor cell viability. PloS One 2013; 8: e68328.

64. French KJ, Upson JJ, Keller SN, Zhuang Y, Yun JK, Smith CD. Antitumor activity of sphingosine kinase inhibitors. J Pharmacol Exp Ther 2006; 318: 596-603.

65. Zhang R, Shah MV, Yang J, Nyland SB, Liu X, Yun JK, et al. Network model of survival signaling in large granular lymphocyte leukemia. Proc Natl Acad Sci USA 2008; 105: 16308-16313.

66. Ratajczak MZ, Lee H, Wysoczynski M, Wan W, Marlicz W, Laughlin MJ, et al. Novel insight into stem cell mobilization-plasma sphingosine-1-phosphate is a major chemoattractant that directs the egress of hematopoietic stem progenitor cells from the bone marrow and its level in peripheral blood increases during mobilization due to activation of complement cascade/membrane attack complex. Leukemia 2010; 24: 976-985.

67. Ratajczak MZ, Kim CH, Abdel-Latif A, Schneider G, Kucia M, Morris AJ, et al. A novel perspective on stem cell homing and mobilization: review on bioactive lipids as potent chemoattractants and cationic peptides as underappreciated modulators of responsiveness to SDF-1 gradients. Leukemia 2012; 26: 63-72.

68. Balabanov S, Braig M, Brummendorf TH. Current aspects in resistance against tyrosine kinase inhibitors in chronic myelogenous leukemia. Drug Discov Today Technol 2014; 11: 89-99.

69. Modugno M. New resistance mechanisms for small molecule kinase inhibitors of Abl kinase. Drug Discov Today Technol 2014; 11: 5-10.

70. Baran Y, Salas A, Senkal CE, Gunduz U, Bielawski J, Obeid LM, et al. Alterations of ceramide/sphingosine 1-phosphate rheostat involved in the regulation of resistance to 
imatinib-induced apoptosis in K562 human chronic myeloid leukemia cells. J Biol Chem 2007; 282: 10922-10934.

71. Weisberg E, Griffin JD. Mechanism of resistance to the ABL tyrosine kinase inhibitor STI571 in BCR/ABL-transformed hematopoietic cell lines. Blood 2000; 95: 3498-3505.

72. le Coutre P, Tassi E, Varella-Garcia M, Barni R, Mologni L, Cabrita G, et al. Induction of resistance to the Abelson inhibitor STI571 in human leukemic cells through gene amplification. Blood 2000; 95: 1758-1766.

73. Barnes DJ, Palaiologou D, Panousopoulou E, Schultheis B, Yong AS, Wong A, et al. BcrAbl expression levels determine the rate of development of resistance to imatinib mesylate in chronic myeloid leukemia. Cancer Res 2005; 65: 8912-8919.

74. Gorre ME, Mohammed M, Ellwood K, Hsu N, Paquette R, Rao PN, et al. Clinical resistance to STI-571 cancer therapy caused by BCR-ABL gene mutation or amplification. Science 2001; 293: 876-880.

75. Marfe G, Di Stefano C, Gambacurta A, Ottone T, Martini V, Abruzzese E, et al. Sphingosine kinase 1 overexpression is regulated by signaling through PI3K, AKT2, and mTOR in imatinib-resistant chronic myeloid leukemia cells. Exp Hematol 2011; 39: 653665 e 656.

76. Burchert A, Wang Y, Cai D, von Bubnoff N, Paschka P, Muller-Brusselbach S, et al. Compensatory PI3-kinase/Akt/mTor activation regulates imatinib resistance development. Leukemia 2005; 19: 1774-1782.

77. Quentmeier H, Eberth S, Romani J, Zaborski M, Drexler HG. BCR-ABL1-independent PI3Kinase activation causing imatinib-resistance. J Hematol Oncol 2011; 4: 6.

78. Airiau K, Mahon FX, Josselin M, Jeanneteau M, Belloc F. PI3K/mTOR pathway inhibitors sensitize chronic myeloid leukemia stem cells to nilotinib and restore the response of progenitors to nilotinib in the presence of stem cell factor. Cell Death Dis 2013; 4: e827.

79. Ding J, Romani J, Zaborski M, MacLeod RA, Nagel S, Drexler HG, et al. Inhibition of $\mathrm{PI} 3 \mathrm{~K} / \mathrm{mTOR}$ overcomes nilotinib resistance in BCR-ABL1 positive leukemia cells through translational down-regulation of MDM2. PloS One 2013; 8: e83510.

80. Okabe S, Tauchi T, Tanaka Y, Kitahara T, Kimura S, Maekawa T, et al. Efficacy of the dual PI3K and mTOR inhibitor NVP-BEZ235 in combination with nilotinib against BCR-ABLpositive leukemia cells involves the ABL kinase domain mutation. Cancer Biol Ther 2014; 15: $207-215$. 
81. Li QF, Huang WR, Duan HF, Wang H, Wu CT, Wang LS. Sphingosine kinase-1 mediates $\mathrm{BCR} / \mathrm{ABL}$-induced upregulation of Mcl-1 in chronic myeloid leukemia cells. Oncogene 2007; 26: 7904-7908.

82. Salas A, Ponnusamy S, Senkal CE, Meyers-Needham M, Selvam SP, Saddoughi SA, et al. Sphingosine kinase-1 and sphingosine 1-phosphate receptor 2 mediate Bcr-Abl1 stability and drug resistance by modulation of protein phosphatase 2A. Blood 2011; 117: 5941-5952.

83. Ricci C, Onida F, Servida F, Radaelli F, Saporiti G, Todoerti K, et al. In vitro antileukaemia activity of sphingosine kinase inhibitor. Br J Haematol 2009; 144: 350-357.

84. Bonhoure E, Lauret A, Barnes DJ, Martin C, Malavaud B, Kohama T, et al. Sphingosine kinase-1 is a downstream regulator of imatinib-induced apoptosis in chronic myeloid leukemia cells. Leukemia 2008; 22: 971-979.

85. Li QF, Yan J, Zhang K, Yang YF, Xiao FJ, Wu CT, et al. Bortezomib and sphingosine kinase inhibitor interact synergistically to induces apoptosis in $\mathrm{BCR} / \mathrm{ABl}+$ cells sensitive and resistant to STI571 through down-regulation Mcl-1. Biochem Biophys Res Commun 2011; 405: 31-36.

86. Rajala HL, Porkka K, Maciejewski JP, Loughran TP, Jr., Mustjoki S. Uncovering the pathogenesis of large granular lymphocytic leukemia-novel STAT3 and STAT5b mutations. Ann Med 2014; 46: 114-122.

87. LeBlanc FR, Liu X, Hengst J, Fox T, Calvert V, Petricoin EF, 3rd, et al. Sphingosine kinase inhibitors decrease viability and induce cell death in natural killer-large granular lymphocyte leukemia. Cancer Biol Ther 2015; 16: 1830-1840.

88. Pui CH, Mullighan CG, Evans WE, Relling MV. Pediatric acute lymphoblastic leukemia: where are we going and how do we get there? Blood 2012; 12: 1165-1174.

89. Wallington-Beddoe CT, Powell JA, Tong D, Pitson SM, Bradstock KF, Bendall LJ. Sphingosine kinase 2 promotes acute lymphoblastic leukemia by enhancing MYC expression. Cancer Res 2014; 74: 2803-2815.

90. Cuvillier O, Levade T. Sphingosine 1-phosphate antagonizes apoptosis of human leukemia cells by inhibiting release of cytochrome $\mathrm{c}$ and Smac/DIABLO from mitochondria. Blood 2001; 98: 2828-2836.

91. Mikawa T, ME LL, Takaori-Kondo A, Inagaki N, Yokode M, Kondoh H. Dysregulated glycolysis as an oncogenic event. Cell Mol Life Sci 2015; 72: 1881-1892. 
92. Shafer D, Grant S. Update on rational targeted therapy in AML. Blood Rev 2016. in press doi: 10.1016/j.blre.2016.02.001.

93. Shatrov VA, Lehmann V, Chouaib S. Sphingosine-1-phosphate mobilizes intracellular calcium and activates transcription factor NF-KB in U937 cells. Biochem Biophys Res Commun 1997; 234: 121-124.

94. Dick TE, Hengst JA, Fox TE, Colledge AL, Kale VP, Sung SS, et al. The apoptotic mechanism of action of the sphingosine kinase 1 selective inhibitor SKI-178 in human acute myeloid leukemia cell lines. J Pharmacol Exp Ther 2015; 352: 494-508.

95. Yang L, Weng W, Sun ZX, Fu XJ, Ma J, Zhuang WF. SphK1 inhibitor II (SKI-II) inhibits acute myelogenous leukemia cell growth in vitro and in vivo. Biochem Biophys Res Commun 2015; 460: 903-908.

96. Bonhoure E, Pchejetski D, Aouali N, Morjani H, Levade T, Kohama T, et al. Overcoming MDR-associated chemoresistance in HL-60 acute myeloid leukemia cells by targeting sphingosine kinase-1. Leukemia 2006; 20: 95-102.

97. Cassaday RD, Goy A, Advani S, Chawla P, Nachankar R, Gandhi M, et al. A Phase II, Single-Arm, Open-Label, Multicenter Study to Evaluate the Efficacy and Safety of P276-00, a Cyclin-Dependent Kinase Inhibitor, in Patients With Relapsed or Refractory Mantle Cell Lymphoma. Clin Lymphom Myeloma Leuk 2015; 15: 392-397.

98. Chong EA, Ahmadi T, Aqui NA, Svoboda J, Nasta SD, Mato AR, et al. Combination of Lenalidomide and Rituximab Overcomes Rituximab Resistance in Patients with Indolent Bcell and Mantle Cell Lymphomas. Clin Cancer Res 2015; 21: 1835-1842.

99. Chen Y, Wang M, Romaguera J. Current regimens and novel agents for mantle cell lymphoma. Br J Haematol 2014; 167: 3-18.

100. Jares P, Colomer D, Campo E. Molecular pathogenesis of mantle cell lymphoma. J Clin Invest 2012; 122: 3416-3423.

101. Nishimura H, Akiyama T, Monobe Y, Matsubara K, Igarashi Y, Abe M, et al. Expression of sphingosine-1-phosphate receptor 1 in mantle cell lymphoma. Mod Pathol 2010; 23: 439449.

102. Bigaud M, Guerini D, Billich A, Bassilana F, Brinkmann V. Second generation S1P pathway modulators: research strategies and clinical developments. Biochim Biophys Acta 2014; 1841: 745-758. 
103. Liu Q, Alinari L, Chen CS, Yan F, Dalton JT, Lapalombella R, et al. FTY720 shows promising in vitro and in vivo preclinical activity by downmodulating Cyclin D1 and phospho-Akt in mantle cell lymphoma. Clin Cancer Res 2010; 16: 3182-3192.

104. Tonelli F, Lim KG, Loveridge C, Long J, Pitson SM, Tigyi G, et al. FTY720 and (S)FTY720 vinylphosphonate inhibit sphingosine kinase 1 and promote its proteasomal degradation in human pulmonary artery smooth muscle, breast cancer and androgenindependent prostate cancer cells. Cell Signal 2010; 22: 1536-1542.

105. Neviani P, Santhanam R, Oaks JJ, Eiring AM, Notari M, Blaser BW, et al. FTY720, a new alternative for treating blast crisis chronic myelogenous leukemia and Philadelphia chromosome-positive acute lymphocytic leukemia. J Clin Invest 2007; 117: 2408-2421.

106. Middle S, Coupland SE, Taktak A, Kidgell V, Slupsky JR, Pettitt AR, et al. Immunohistochemical analysis indicates that the anatomical location of B-cell nonHodgkin's lymphoma is determined by differentially expressed chemokine receptors, sphingosine-1-phosphate receptors and integrins. Exp Hematol Oncol 2015; 4: 10.

107. Pfeifer M, Zheng B, Erdmann T, Koeppen H, McCord R, Grau M, et al. Anti-CD22 and anti-CD79B antibody drug conjugates are active in different molecular diffuse large B-cell lymphoma subtypes. Leukemia 2015; 29: 1578-1586.

108. Scuto A, Kujawski M, Kowolik C, Krymskaya L, Wang L, Weiss LM, et al. STAT3 inhibition is a therapeutic strategy for ABC-like diffuse large B-cell lymphoma. Cancer Res 2011; 71: 3182-3188.

109. Lee H, Deng J, Kujawski M, Yang C, Liu Y, Herrmann A, et al. STAT3-induced S1PR1 expression is crucial for persistent STAT3 activation in tumors. Nat Med 2010; 16: 14211428.

110. Liu Y, Deng J, Wang L, Lee H, Armstrong B, Scuto A, et al. S1PR1 is an effective target to block STAT3 signaling in activated B cell-like diffuse large B-cell lymphoma. Blood 2012; 120: $1458-1465$.

111. Paik JH, Nam SJ, Kim TM, Heo DS, Kim CW, Jeon YK. Overexpression of sphingosine-1phosphate receptor 1 and phospho-signal transducer and activator of transcription 3 is associated with poor prognosis in rituximab-treated diffuse large B-cell lymphomas. BMC Cancer 2014; 14: 911.

112. Koresawa R, Yamazaki K, Oka D, Fujiwara H, Nishimura H, Akiyama $\mathrm{T}$, et al. Sphingosine-1-phosphate receptor 1 as a prognostic biomarker and therapeutic target for patients with primary testicular diffuse large B-cell lymphoma. Br J Haematol 2016, in press, doi: 10.1111/bjh.14054. 
982

983

984

985

986

987

988

989

990

991

992

993

994

995

996

997

998

999

1000

1001

1002

1003

1004

1005

1006

1007

1008

1009

1010

1011

1012

1013

113. Castillo JJ, Shum H, Lahijani M, Winer ES, Butera JN. Prognosis in primary effusion lymphoma is associated with the number of body cavities involved. Leuk Lymphoma 2012; 53: $2378-2382$.

114. Okada S, Goto H, Yotsumoto M. Current status of treatment for primary effusion lymphoma. Intractable Rare Dis Res 2014; 3: 65-74.

115. Qin Z, Dai L, Trillo-Tinoco J, Senkal C, Wang W, Reske T, et al. Targeting sphingosine kinase induces apoptosis and tumor regression for KSHV-associated primary effusion lymphoma. Mol Cancer Ther 2014; 13: 154-164.

116. Shain KH, Dalton WS, Tao J. The tumor microenvironment shapes hallmarks of mature Bcell malignancies. Oncogene 2015; 34: 4673-4682.

117. Yasui H, Hideshima T, Raje N, Roccaro AM, Shiraishi N, Kumar S, et al. FTY720 induces apoptosis in multiple myeloma cells and overcomes drug resistance. Cancer Res 2005; 65: $7478-7484$.

118. Yasui H, Hideshima T, Richardson PG, Anderson KC. Novel therapeutic strategies targeting growth factor signalling cascades in multiple myeloma. Br J Haematol 2006; 132: 385-397.

119. Tsukamoto S, Huang Y, Kumazoe M, Lesnick C, Yamada S, Ueda N, et al. Sphingosine Kinase-1 Protects Multiple Myeloma from Apoptosis Driven by Cancer-Specific Inhibition of RTKs. Mol Cancer Ther 2015; 14: 2303-2312.

120. Mori Y, Shimizu N, Dallas M, Niewolna M, Story B, Williams PJ, et al. Anti- $\alpha 4$ integrin antibody suppresses the development of multiple myeloma and associated osteoclastic osteolysis. Blood 2004; 104: 2149-2154.

121. Sanz-Rodriguez F, Hidalgo A, Teixido J. Chemokine stromal cell-derived factor-1 $\alpha$ modulates VLA-4 integrin-mediated multiple myeloma cell adhesion to CS-1/fibronectin and VCAM-1. Blood 2001; 97: 346-351.

122. Garcia-Bernal D, Redondo-Munoz J, Dios-Esponera A, Chevre R, Bailon E, Garayoa M, et al. Sphingosine-1-phosphate activates chemokine-promoted myeloma cell adhesion and migration involving $\alpha 4 \beta 1$ integrin function. J Pathol 2013; 229: 36-48.

123. Venkata JK, An N, Stuart R, Costa LJ, Cai H, Coker W, et al. Inhibition of sphingosine kinase 2 downregulates the expression of c-Myc and Mcl-1 and induces apoptosis in multiple myeloma. Blood 2014; 124: 1915-1925. 


\section{Figure legends}

Figure 1. Sphingolipid metabolism. Ceramide can be synthesized de novo or generated through the breakdown of sphingomyelin or complex glycosphingolipids (not shown) or by the acetylation of sphingosine. Phosphorylation of sphingosine by SPHK generates S1P. SMase: Sphingomyelinase. SMsynthase: Sphingomyelin synthase.

Figure 2. Domain organization of SPHK isoforms and splice variants. Blue represents untranslated exon regions while grey represents translated exon regions. All SPHK isoforms have five highly conserved regions: a catalytic domain (yellow), a lipid binding domain (black) and three ATP binding domains (red), one of which is split across an intron.

Figure 3. Role of SPHK/S1P signaling in CML. Imatinib resistance (red arrows) in CML is associated with elevated expression of BCR/ABL1 and SPHK1 (which may involve increased PI3K/Akt/mTOR, ERK-1/2 and JAK2 signaling). Over-expression of SPHK1 enhances $\mathrm{BCR} / \mathrm{ABL} 1$ levels via $\mathrm{S}_{1} \mathrm{P}_{2}$-mediated inhibition of $\mathrm{PP} 2 \mathrm{~A}$, thereby preventing the dephosphorylation of BCR/ABL1 and reducing subsequent proteasomal degradation of BCR/ABL1. Over-expressed SPHK1 also maintains expression of the pro-survival protein, Mcl-1. Pharmacological inhibition of $\mathrm{SPHK} 1 / \mathrm{S} 1 \mathrm{P}_{2}$ or activation of PP2A (black double arrows) counteracts these events and restores imatinib sensitivity.

\section{Figure 4. Role of $\mathrm{S1P}_{1}$ in NHL sub-type, activated ABC-DLBCL.}

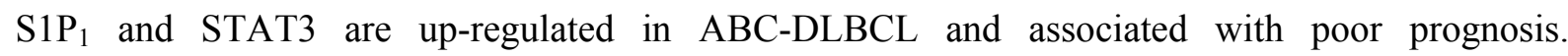
Knockdown of $\mathrm{S}_{1} \mathrm{P}_{1}$ using shRNA indirectly reduces STAT3 phosphorylation levels and inhibits tumor growth. The pro-drug FTY720 is phosphorylated by SPHK2 to FTY720-phosphate. This is released, binds to $\mathrm{S}_{1} \mathrm{P}_{1}$ and induces proteasomal degradation of this receptor. The reduction of $\mathrm{S}_{1} \mathrm{P}_{1}$ levels inhibits tumor growth in vitro and in vivo. 
Table 1. The roles of SPHK and S1P in malignant hematological disorders.

\begin{tabular}{|c|c|c|}
\hline Disorder & Component & Roles \\
\hline \multirow[t]{2}{*}{ CML } & SPHK1 & $\begin{array}{l}\text { Enhanced expression by BCR/ABL1 and vice versa } \\
\text { Inhibition results in cytotoxicity and enhances imatinib } \\
\text { sensitivity }{ }^{68}\end{array}$ \\
\hline & S1P & $\begin{array}{l}\text { Up-regulates anti-apoptotic } \mathrm{Mcl}-1^{79} \\
\text { Binding to } \mathrm{S}_{1} \mathrm{P}_{2} \text { inhibits } \mathrm{PP} 2 \mathrm{~A}-\text { dependent } \mathrm{BCR} / \mathrm{ABL} 1 \\
\text { dephosphorylation } 80\end{array}$ \\
\hline T-LGL & SPHK1 & $\begin{array}{l}\text { Activity stimulated by PDGF. Inhibition results in apoptosis } \\
65\end{array}$ \\
\hline NK-LGL & SPHK1 & Enhanced expression. Inhibition results in apoptosis ${ }^{85}$ \\
\hline \multirow[t]{2}{*}{ AML } & SPHK1 & $\begin{array}{l}\text { Inhibition results in cytotoxicity of U937 xenografts in mice } \\
27 \\
\text { Inhibition induces HL-60 cell cytotoxicity and sensitizes } \\
\text { chemoresistant HL-60 cells }{ }^{93}\end{array}$ \\
\hline & $\mathrm{S} 1 \mathrm{P}$ & $\begin{array}{l}\text { Elicits mitogenic signals through NF- } \kappa \text { B activation in U937 } \\
\text { cells }{ }^{90} \\
\text { Inhibits apoptosis in U937 and HL-60 cells }{ }^{88}\end{array}$ \\
\hline B-ALL & SPHK2 & Oncogenic in mouse through c-MYC ${ }^{87}$ \\
\hline \multirow[t]{3}{*}{ T-ALL } & SPHK1 & Inhibition results in apoptosis ${ }^{57}$ \\
\hline & SPHK2 & Inhibition results in autophagic cell death ${ }^{57}$ \\
\hline & S1P & Induces apoptosis $^{88}$ \\
\hline NHL & SPHK1 & Enhanced expression $^{25}$ \\
\hline \multirow[t]{2}{*}{ PEL } & SPHK2 & Inhibition results in apoptosis ${ }^{112}$ \\
\hline & S1P & $\begin{array}{l}\text { Regulates ERK 1/2, PI3K/Akt/mTOR, and NF- } \mathrm{KB} \text { signaling } \\
112\end{array}$ \\
\hline \multirow[t]{3}{*}{ MM } & SPHK1 & $\begin{array}{l}\text { Inhibition prevents receptor tyrosine kinase phosphorylation } \\
\text { and activation of DAPK1 } 116\end{array}$ \\
\hline & SPHK2 & $\begin{array}{l}\text { Over-expressed in MM cells. Inhibition results in down- } \\
\text { regulation of cell proliferation and enhanced apoptosis } 120\end{array}$ \\
\hline & S1P & Plays a role in MM cell adhesion ${ }^{117}$ \\
\hline
\end{tabular}





\section{PalmitoylCoA + Serine}

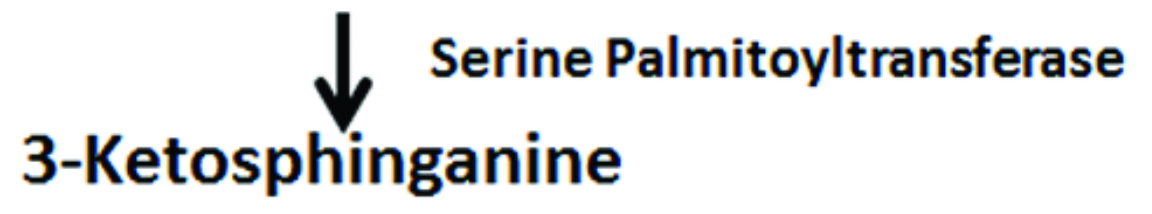

$\downarrow$ Ketosphingosine Reductase

\section{Dihydrosphingosine}

\section{W Ceramide Synthase}

\section{Dihydroceramide}

SMase

\section{Sphingomyelin}

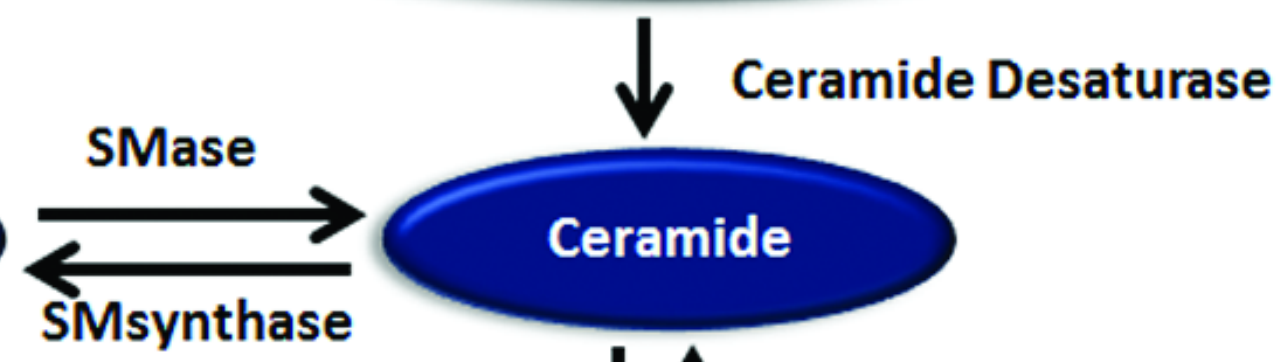

Ceramidase $\downarrow$ 个 Ceramide Synthase

\section{Sphingosine}

\section{SPHKS $\downarrow \uparrow \begin{aligned} & \text { S1P phosphatases/lipid } \\ & \text { phosphate phosphatases }\end{aligned}$}

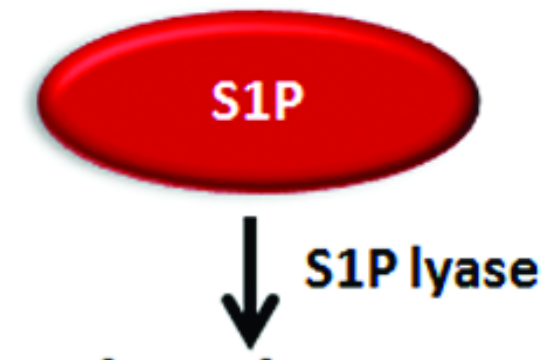



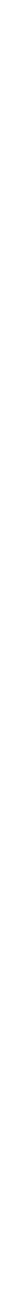

Figure 2 


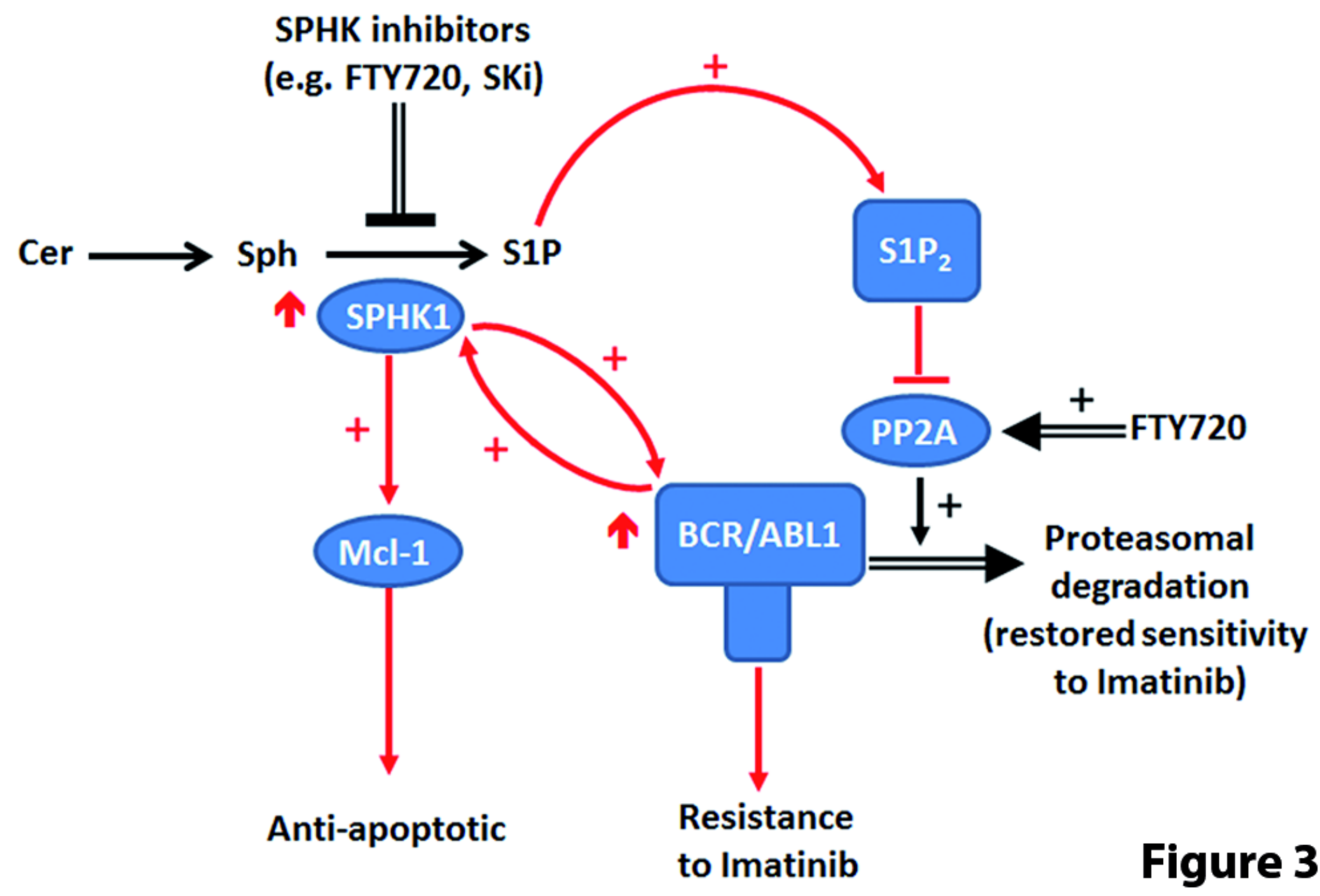




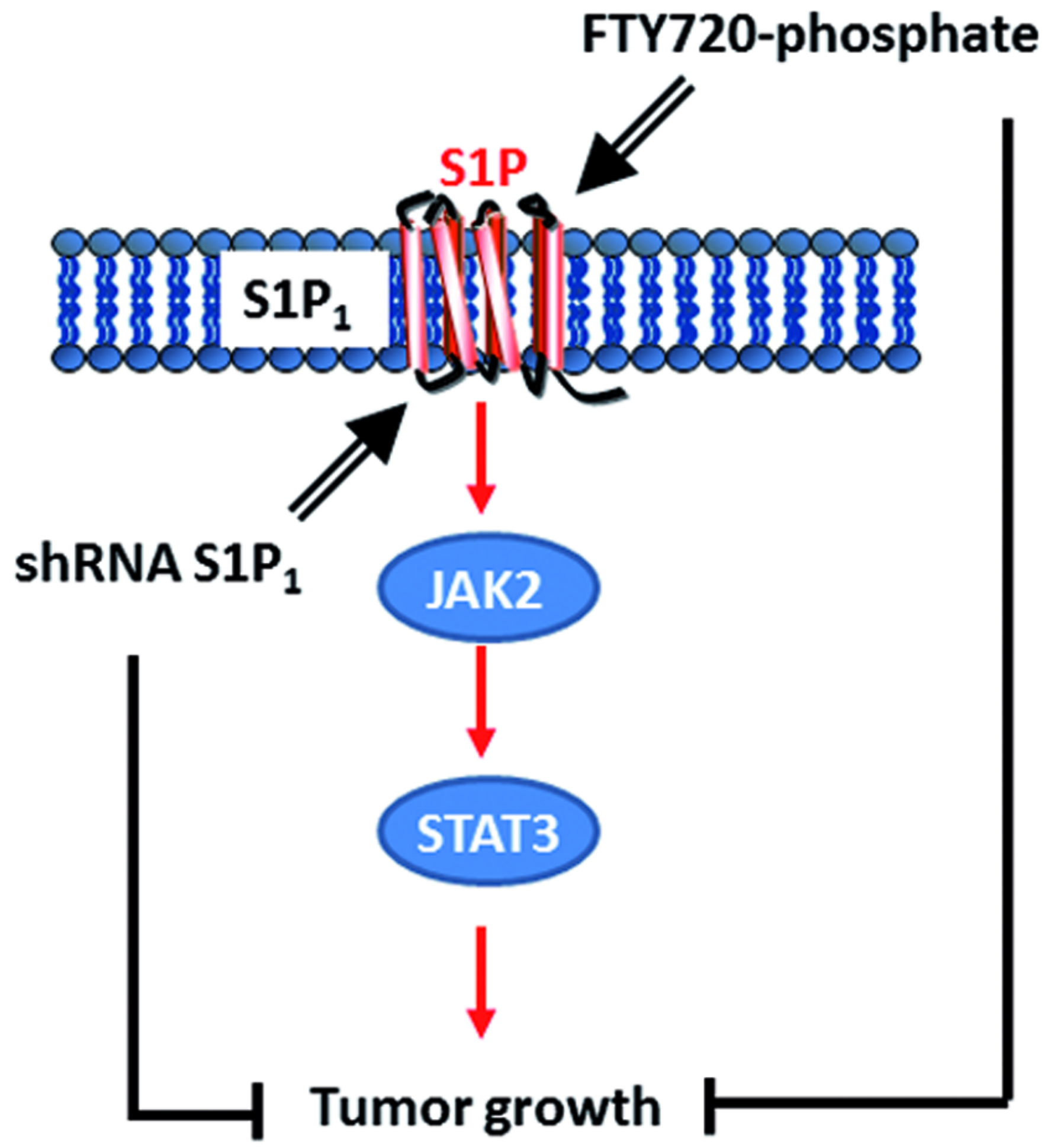

Figure 4 